\title{
Radiographic Progression in Patients With Ankylosing Spondylitis According to Uveitis Based on the Observation Study of Korean Spondyloarthropathy Registry
}

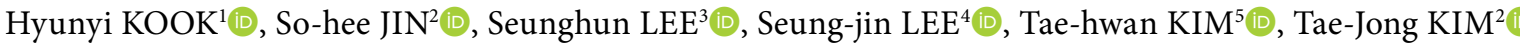 \\ ${ }^{1}$ Chonnam National University Medical School, College of Nursing, Gwangju, South Korea \\ ${ }^{2}$ Department of Rheumatology, Chonnam National University Medical School and Hospital, Gwangju, South Korea \\ ${ }^{3}$ Department of Radiology, Hanyang University Hospital for Rheumatic Diseases, Seou, South Korea \\ ${ }^{4}$ Department of Radiology, Chonnam National University Medical School and Hospital, Gwangju, South Korea \\ ${ }^{5}$ Department of Rheumatology, Hanyang University Hospital for Rheumatic Diseases, Seoul, South Korea
}

\section{ABSTRACT}

Objectives: This study aims to investigate radiographic progression according to the presence or absence of uveitis in patients with ankylosing spondylitis (AS).

Patients and methods: A total of 598 patients (529 males, 69 females, mean age $38.1 \pm 9.2$ years; range, 18 to 73 years) from the Observation Study of Korean Spondyloarthropathy Registry who met the modified New York criteria for AS were included in this study. At baseline, all data were stratified into two groups according to the presence or absence of uveitis. Baseline and radiographic progression were assessed for five years in this registry. Modified Stoke Ankylosing Spondylitis Spinal Score (mSASSS) was read by two radiologists. Reliability was assessed using inter- and intra-class correlation coefficient for each radiograph. Comparison of mSASSS changes was analyzed by analysis of covariance model after adjusting for confounding factors.

Results: The evaluation of mSASSS showed good agreement between the two readers. A total of 193 patients ( $32.27 \%$ ) had a history of uveitis that presented at a mean age of 39.6 years, including 30 females $(15.54 \%)$. There were statistically significant differences in age ( $p=0.01)$, sex $(p=0.04)$, hip joint involvement $(p<0.01)$, and human leukocyte antigen B27 carrier state $(p=0.02)$ between the two groups according to uveitis. A simple comparison revealed no significant difference in mSASSS change for five years between the two groups (mean: $3.05 \pm 0.62$ vs. $3.78 \pm 0.78, p=0.47$ ). After adjusting for confounding factors in multiple comparisons by Bonferroni correction, patients with uveitis had no significant association with mSASSS change for five years (mean: $6.29 \pm 1.32$ vs. $5.49 \pm 1.39, p=0.68$ ).

Conclusion: Our study confirms that there is no significant association between uveitis and radiographic progression in patients with AS after adjusting for confounding factors.

Keywords: Ankylosing spondylitis, radiographic progression, uveitis.

Ankylosing spondylitis (AS) is a chronic, systemic, and inflammatory rheumatic disease that primarily influences the axial skeleton with variable involvement of peripheral joints and extra-articular organs. ${ }^{1}$ The prevalence of AS ranges from 0.1 to $0.4 \%$ in the general population.
It typically influences young adults, with onset age of 20 to 30 years. ${ }^{2,3}$ The most specific and typical symptom of AS is pain in lumbar and gluteal areas. ${ }^{4}$ Extra-articular manifestations of AS have also been frequently reported, with eyes being the most commonly involved. ${ }^{5}$ Uveitis,

Received: July 04, 2018 Accepted: March 11, 2019 Published online: April 22, 2019

Correspondence: Tae-Jong Kim, MD. Department of Rheumatology, Chonnam National University Medical School and Hospital, 503-340 Gwangju, South Korea. Tel: +82-626709494 e-mail: ktj1562@jnu.ac.kr 
inflammation of the anterior uvea containing iris and ciliary body, has been positively associated with disease progression of AS and occurs in 30 to $40 \%$ of patients with AS. ${ }^{6-8}$ Symptoms of acute anterior uveitis (AAU) generally include an acute onset of eye redness and pain, intense photophobia, blepharospasm, and myosis that will eventually lead to reduction in visual acuity. ${ }^{9}$ The association between uveitis and AS has been well recognized. ${ }^{8,10,11}$ However, the relationship between spinal bone formation and uveitis in patients with AS has been rarely reported. In addition, to our knowledge, previous studies did not focus on radiographic progression with regard to uveitis in AS. Therefore, in this study, we aimed to investigate radiographic progression according to the presence or absence of uveitis in patients with AS.

\section{PATIENTS AND METHODS}

The Observation Study of Korean Spondyloarthropathy (SpA) Registry (OSKAR) is a longitudinal ongoing observational study on clinical, functional, and structural outcomes of SpA in Korea. ${ }^{1}$ A total of 598 patients (529 males, 69 females, mean age $38.1 \pm 9.2$ years; range, 18 to 73 years) from OSKAR who met the modified New York criteria for $\mathrm{AS}^{12}$ were included in this study that was conducted at Hanyang University Hospital for Rheumatic Diseases, and Chonnam National University Hospital between May 2007 and July 2015. At baseline, all data were stratified into two groups according to the presence or absence of uveitis. Among them, subjects with available radiographic and clinical data were enrolled consecutively. After that, we examined radiographic spinal progression at follow-up. The study protocol was approved by the Hanyang University Hospital for Rheumatic Diseases, and Chonnam National University Hospital Ethics Committee. A written informed consent was obtained from each patient. The study was conducted in accordance with the principles of the Declaration of Helsinki.

Radiographs were scored independently by two radiologists. All clinical parameters were blinded to readers. Because the modified Stoke Ankylosing Spondylitis Spinal Score (mSASSS) was identified as the most sensitive method, ${ }^{13}$ cervical and lumbar spinal X-rays were used. We excluded radiographs with more than three vertebral sites missing. If fewer than three vertebral sites were missing, missing scores were substituted by the mean score of the vertebra of the same spinal region of the patient according to a previous paper. ${ }^{14}$

All clinical values were confirmed by rheumatologists participated in our registry. Clinical data included sex, age, duration of disease, juvenile-onset AS (JoAS), peripheral arthritis, uveitis, family history of AS, and use of biologics. Hip X-rays were not available for all patients in our cohort. Therefore, involvement of the hip was assessed based on clinical findings according to the rheumatologist's clinical perception. Nonsteroidal anti-inflammatory drug (NSAID) index was also calculated according to recommendations..$^{15}$ Family history was defined as whether the patient had any first-degree relatives (parents, siblings, or off-spring) diagnosed with AS. Laboratory tests included C-reactive protein (CRP), erythrocyte sedimentation rate (ESR) level, and human leukocyte antigen (HLA) B27 status. All cases with uveitis were confirmed by an ophthalmologist.

\section{Statistical analysis}

Intra- and inter-reader reliabilities were assessed using intra-class correlation coefficient (ICC) for each radiograph. Clinical comparisons for continuous variables were performed using t-test. Chi-square test was used to compare categorical variables. Comparison of mSASSS changes was assessed by analysis of covariance (ANCOVA) model after adjusting for confounding factors using Bonferroni correction. $\mathrm{P}$ values lower than 0.05 were accepted as statistically significant.

\section{RESULTS}

Agreement between the two readers was very good, with ICC for intra- and inter-reader reliabilities of $0.75(95 \%$ confidence interval $[\mathrm{CI}$ : 0.61-0.82) and 0.71 (95\% CI: 0.58-0.82), respectively. Agreement regarding mSASSS change was moderate, with ICC of 0.57 (95\% CI: 0.47-0.68) for intra-reader reliability and 0.64 (95\% CI: 0.45-0.76) for inter-reader reliability. 
Table 1. Comparison of baseline characteristics of patients with or without uveitis

\begin{tabular}{|c|c|c|c|c|c|c|c|}
\hline & \multicolumn{3}{|c|}{ Uveitis present $(n=193)$} & \multicolumn{3}{|c|}{ Uveitis absent $(n=405)$} & \multirow[b]{2}{*}{$p$} \\
\hline & $\mathrm{n}$ & $\%$ & Mean \pm SD & $\mathrm{n}$ & $\%$ & Mean \pm SD & \\
\hline Age (year) & & & $39.7 \pm 9.2$ & & & $37.4 \pm 9.2$ & 0.01 \\
\hline $\begin{array}{l}\text { Sex } \\
\quad \text { Female }\end{array}$ & 30 & 15.54 & & 39 & 9.63 & & 0.04 \\
\hline Duration (year) & & & $20.8 \pm 5.7$ & & & $20.8 \pm 5.7$ & 0.91 \\
\hline Family history of AS & 40 & 20.73 & & 59 & 14.57 & & 0.39 \\
\hline JoAS & 41 & 21.24 & & 73 & 18.02 & & 0.57 \\
\hline Peripheral arthritis & 85 & 44.04 & & 153 & 37.8 & & 0.15 \\
\hline Hip joint involvement & 113 & 58.5 & & 172 & 42.5 & & $<0.01$ \\
\hline HLA-B27 positivity & 184 & 95.33 & & 375 & 92.59 & & 0.02 \\
\hline Use of biologics & 106 & 54.92 & & 165 & 40.74 & & 0.09 \\
\hline mSASSS & & & $18.8 \pm 16.9$ & & & $17.1 \pm 17.1$ & 0.26 \\
\hline $\mathrm{ESR}(\mathrm{mm} / \mathrm{h})$ & & & $58.7 \pm 37.1$ & & & $50.3 \pm 37.5$ & 0.07 \\
\hline CRP (mg/dL) & & & $4.0 \pm 3.7$ & & & $3.5 \pm 3.3$ & 0.23 \\
\hline
\end{tabular}

We examined the baseline demographics and clinical features of 598 patients (Table 1). A total of 193 patients (32.27\%) had history of uveitis with a mean (standard deviation [SD]) age of 39.65 (9.22) years while a total of 405 individuals $(67.72 \%)$ had no history of uveitis with a mean (SD) age of 37.41 (9.16) years. There were statistically significant differences in age $(p=0.01)$, sex $(p=0.04)$, hip joint involvement $(p<0.01)$, and HLA-B27 carrier state $(p=0.02)$ between the two groups of patients with or without uveitis. However, there were no significant differences in duration of disease, family history of AS, JoAS, peripheral arthritis, use of biologics, baseline mSASSS, ESR, or CRP between the two groups. With simple comparison, there was no significant difference in mSASSS at baseline (mean 18.81 [SD 16.94] vs. 17.10 [17.09], $p=0.26)$ between the two groups. At two-year follow-up, radiographic progression was not significant between the two groups (mean 1.18 [standard error of mean (SEM) 6.10] vs. 1.97 (6.59), $p=0.16$, data not shown). A simple comparison revealed no significant difference in mSASSS change for five years (mean 3.05 [SEM 0.62] vs. 3.78 [SEM 0.78, $p=0.46]$ ) (Figure 1). During the five-year follow-up, patients with one episode ( $n=114,59.1 \%)$, two episodes $(n=39,20.2 \%)$, and more than three episodes $(n=40,20.7 \%)$ were observed. Therefore, we analyzed mSASSS change according to frequencies of uveitis. However, the frequency of uveitis did not affect radiographic change $(p=0.89)$.

We re-analyzed mSASSS change using ANCOVA model because radiographic progression might be affected by clinical parameters. Confounding clinical factors were age, sex, disease duration, baseline mSASSS, hip joint involvement, ESR, NSAID index, and use of biologics. NSAID indices were not statistically significant between the two groups $(49.2 \pm 34.1$ in the non-uveitis group vs. $44.0 \pm 35.4$ in the uveitis group, $p=0.93$ ). Fourteen patients in the non-uveitis group at baseline developed uveitis during the five-year follow-up period. They had

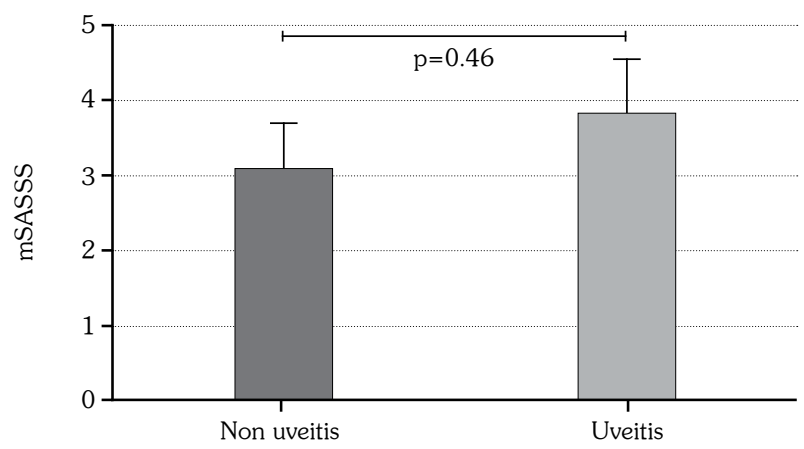

Figure 1. Comparison of radiographic progression scores for all patients in the two groups. mSASSS: Modified Stoke Ankylosing Spondylitis Spinal Score. 
Table 2. Radiographic progression between patients with or without uveitis

\begin{tabular}{|c|c|c|c|c|}
\hline \multirow{2}{*}{$\begin{array}{l}\text { Dependent variable: mSASSS progression } \\
\text { Uveitis }\end{array}$} & \multirow[b]{2}{*}{ Mean \pm SE } & \multicolumn{2}{|c|}{$95 \% \mathrm{CI}$} & \multirow[b]{2}{*}{$p$} \\
\hline & & Lower bound & Upper bound & \\
\hline Absence & 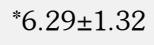 & 3.67 & 8.93 & \multirow{2}{*}{0.68} \\
\hline Presence & $* 5.49 \pm 1.39$ & 2.72 & 8.25 & \\
\hline
\end{tabular}

variable onset times of uveitis. Therefore, their radiographic data were excluded from analysis with the ANCOVA model. After adjusting for confounding factors in multiple comparisons by Bonferroni correction, patients with history of uveitis had no significant association with mSASSS change for five years (mean 6.29 [SEM 1.32] vs. 5.49 [1.39], $\mathrm{p}=0.68$ ) (Table 2).

\section{DISCUSSION}

Because chronic inflammation of spine in AS causes progressive visible structural damage, there has been considerable interest in factors affecting radiologic change in patients with AS. However, there have been controversial results on radiographic progression regarding uveitis. One study has shown that history of uveitis is significantly associated with higher radiological score using Bath Ankylosing Spondylitis Radiology Index (BASRI). ${ }^{16}$ On the other hand, Gehlen et al. ${ }^{5}$ have reported that BASRI scores are not significantly different between patients with or without uveitis $(6.4 \pm 4.5$ vs. $7.3 \pm 5.0, p=0.46)$ in a cross-sectional study. Chen et al. ${ }^{17}$ have also demonstrated that uveitis does not affect radiographic spinal involvement using both BASRI and mSASSS for patients in Taiwan. Recently, multivariable analysis results from Outcome in Ankylosing Spondylitis International Study cohort have shown that AAU is no longer associated with radiographic damage over time. ${ }^{18}$ In the same line, our simple comparison revealed no differences in mSASSS change for five years. It has been reported that uveitis is associated with extensive radiographic progression in male patients by using BASRI through logistic regression analysis. ${ }^{19}$ In the present study using the same logistic regression analysis, there was no significant mSASSS change in males regarding uveitis $(3.4 \pm 0.7$ in non-uveitis, $4.4 \pm 0.9$ in uveitis, $\mathrm{p}=0.37$ ).

Hip joint involvement is an important feature in AS. An observational study on 390 AS patients has reported that the prevalence of hip joint involvement is higher in the uveitis group. ${ }^{2}$ Sampaio-Barros et al. ${ }^{20}$ have also shown that anterior uveitis is significantly associated with hip involvement. Patients with hip involvement have worse scores in mSASSS. ${ }^{17}$ Although hip involvement was based on clinical findings according to the rheumatologist's clinical perception in the present study, our data also showed significant correlation between uveitis and hip joint involvement. CRP level is an independent predictor for radiographic spinal progression in AS. ${ }^{21}$ NSAIDs can retard new bone formation in AS patients. ${ }^{22}$ Results from a German Spondyloarthritis Inception cohort have confirmed that progression of the structural damage in the spine is strongly dependent on the presence of already occurred damage. ${ }^{23}$ When all clinical parameters related to radiographic progression were considered, our prospective results did not show significant correlation between uveitis and radiographic progression.

There has been considerable interest in the risk of uveitis for patients with AS. . $, 7,10,11,24^{\text {The }}$ strong correlation of AS with uveitis is supposed to be related to the presence of HLA-B27. ${ }^{11,25}$ It has been reported that about 30 to $50 \%$ of subjects with uveitis are related to the presence of HLA-B27 and that HLA-B27 positive patients have a 3.8-fold greater possibility of developing uveitis than HLA-B27 negative patients. ${ }^{7}$ Such positive association between HLA-B27 and uveitis is also supported by our results, although a few studies have shown no difference in HLA-B27 between those with or without a 
history of uveitis. ${ }^{2,5}$ Several established reports have shown no association between sex and uveitis. ${ }^{5,8,26}$ Rusman et al. ${ }^{27}$ have reported that acute anterior uveitis is more prevalent in male patients. On the contrary, we found that females seemed to have higher prevalence of uveitis in comparison with males $(43.5 \%$ vs. $30.8 \%, p=0.04)$, similar to our previous study. ${ }^{1}$ This discrepancy may be explained by regional and ethnic differences. Female and HLA-B27 positive patients were more likely to have uveitis in our cohort. Thus, we should pay attention to patients with these risk factors in the early state of the disease.

This study has some limitations. Magnetic resonance imaging is the most sensitive imaging modality for early detection of spine and sacroiliac joint changes in AS. Recently, post-inflammatory fatty lesions seem to be predictable for the formation of new syndesmophytes. ${ }^{28}$ However, this study was based on conventional radiographic imaging only. Furthermore, although smoking could have important effects on radiographic change, ${ }^{23}$ such data were not included in this study.

In conclusion, this study was focused on uveitis and radiologic progression for five years in a sequence with large and well-classified samples. Our study confirmed that there was no association between uveitis and radiographic progression in patients with AS after adjusting for confounding factors.

\section{Declaration of conflicting interests}

The authors declared no conflicts of interest with respect to the authorship and/or publication of this article.

\section{Funding}

This study was supported by grants from the National Research Foundation of Korea (NRF) Grant funded by the Ministry of Education, Science, and Technology (grant no. NRF-2017R1A2B4007994), and by the Chonnam National University Hospital Biomedical Research Institute (grant no. CRI 17020-1).

\section{REFERENCES}

1. Kim TJ, Kim TH. Clinical spectrum of ankylosing spondylitis in Korea. Joint Bone Spine 2010;77:235-40.
2. Sun $L$, Wu R, Xue Q, Wang F, Lu P. Risk factors of uveitis in ankylosing spondylitis: An observational study. Medicine (Baltimore) 2016;95:e4233.

3. Dakwar E, Reddy J, Vale FL, Uribe JS. A review of the pathogenesis of ankylosing spondylitis. Neurosurg Focus 2008;24:E2.

4. Westerveld LA, van Bemmel JC, Dhert WJ, Oner FC, Verlaan JJ. Clinical outcome after traumatic spinal fractures in patients with ankylosing spinal disorders compared with control patients. Spine J 2014;14:729-40.

5. Gehlen M, Regis KC, Skare TL. Demographic, clinical, laboratory and treatment characteristics of spondyloarthritis patients with and without acute anterior uveitis. Sao Paulo Med J 2012;130:141-4.

6. Lu MC, Hsu BB, Koo M, Lai NS. Higher risk of incident ankylosing spondylitis in patients with uveitis: a secondary cohort analysis of a nationwide, population-based health claims database. Scand J Rheumatol 2017;46:468-73.

7. Gouveia EB, Elmann D, Morales MS. Ankylosing spondylitis and uveitis: overview. Rev Bras Reumatol 2012;52:742-56.

8. Chen $\mathrm{CH}$, Lin KC, Chen HA, Liao HT, Liang TH, Wang HP, et al. Association of acute anterior uveitis with disease activity, functional ability and physical mobility in patients with ankylosing spondylitis: a cross-sectional study of Chinese patients in Taiwan. Clin Rheumatol 2007;26:953-7.

9. Zeboulon N, Dougados M, Gossec L. Prevalence and characteristics of uveitis in the spondyloarthropathies: a systematic literature review.Ann Rheum Dis 2008;67:955-9.

10. Fernández-Melón J, Muñoz-Fernández S, Hidalgo V, Bonilla-Hernán G, Schlincker A, Fonseca A, et al. Uveitis as the initial clinical manifestation in patients with spondyloarthropathies. J Rheumatol 2004;31:524-7.

11. Mitulescu TC, Popescu C, Naie A, PredeПeanu D, Popescu V, Alexandrescu C, et al. Acute anterior uveitis and other extra-articular manifestations of spondyloarthritis. J Med Life 2015;8:319-25.

12. van der Linden S, Valkenburg HA, Cats A. Evaluation of diagnostic criteria for ankylosing spondylitis. A proposal for modification of the New York criteria. Arthritis Rheum 1984;27:361-8.

13. Creemers MC, Franssen MJ, van't Hof MA, Gribnau FW, van de Putte LB, van Riel PL. Assessment of outcome in ankylosing spondylitis: an extended radiographic scoring system. Ann Rheum Dis 2005;64:127-9.

14. Baraliakos X, Listing J, Rudwaleit M, Brandt J, Sieper $\mathrm{J}$, Braun J. Radiographic progression in patients with ankylosing spondylitis after 2 years of treatment with the tumour necrosis factor alpha antibody infliximab. Ann Rheum Dis 2005;64:1462-6.

15. Dougados M, Simon P, Braun J, Burgos-Vargas R, Maksymowych WP, Sieper J, et al. ASAS 
recommendations for collecting, analysing and reporting NSAID intake in clinical trials/ epidemiological studies in axial spondyloarthritis. Ann Rheum Dis 2011;70:249-51.

16. Doran MF, Brophy S, MacKay K, Taylor G, Calin A. Predictors of longterm outcome in ankylosing spondylitis. J Rheumatol 2003;30:316-20.

17. Chen HA, Chen $\mathrm{CH}$, Liao HT, Lin YJ, Chen PC, Chen WS, et al. Factors associated with radiographic spinal involvement and hip involvement in ankylosing spondylitis. Semin Arthritis Rheum 2011;40:552-8.

18. Essers I, Ramiro S, Stolwijk C, Blaauw M, Landewé $\mathrm{R}$, van der Heijde $\mathrm{D}$, et al. Do extra-articular manifestations influence outcome in ankylosing spondylitis? 12-year results from OASIS. Clin Exp Rheumatol 2016;34:214-21.

19. Atagunduz P, Aydin SZ, Bahadir C, Erer B, Direskeneli $\mathrm{H}$. Determinants of early radiographic progression in ankylosing spondylitis. J Rheumatol 2010;37:2356-61.

20. Sampaio-Barros PD, Pereira IA, Hernández-Cuevas C, Berman A, Burgos-Vargas R, Gutierrez MA,et al. An analysis of 372 patients with anterior uveitis in a large Ibero-American cohort of spondyloarthritis: the RESPONDIA Group. Clin Exp Rheumatol 2013;31:484-9.

21. Poddubnyy D, Rudwaleit M, Haibel H, Listing J, Märker-Hermann $\mathrm{E}$, Zeidler $\mathrm{H}$, et al. Rates and predictors of radiographic sacroiliitis progression over 2 years in patients with axial spondyloarthritis.
Ann Rheum Dis 2011;70:1369-74.

22. Poddubnyy D, Haibel H, Listing J, Märker-Hermann $\mathrm{E}$, Zeidler $\mathrm{H}$, Braun $\mathrm{J}$, et al. Baseline radiographic damage, elevated acute-phase reactant levels, and cigarette smoking status predict spinal radiographic progression in early axial spondylarthritis. Arthritis Rheum 2012;64:1388-98.

23. Poddubnyy D, Rudwaleit M, Haibel H, Listing J, MärkerHermann E, Zeidler $\mathrm{H}$, et al. Effect of non-steroidal anti-inflammatory drugs on radiographic spinal progression in patients with axial spondyloarthritis: results from the German Spondyloarthritis Inception Cohort. Ann Rheum Dis 2012;71:1616-22.

24. Yen JC, Hsu CA, Hsiao SH, Hsu MH. Acute anterior uveitis as a risk factor of ankylosing spondylitis-a national population-based study. Int $\mathrm{J}$ Environ Res Public Health 2017;14. pii: E107

25. Suhler EB, Martin TM, Rosenbaum JT. HLA-B27associated uveitis: overview and current perspectives. Curr Opin Ophthalmol 2003;14:378-83.

26. Gran JT, Skomsvoll JF. The outcome of ankylosing spondylitis: a study of 100 patients. Br J Rheumatol 1997;36:766-71.

27. Rusman $\mathrm{T}$, van Vollenhoven RF, van der HorstBruinsma IE. Gender Differences in Axial Spondyloarthritis: Women Are Not So Lucky. Curr Rheumatol Rep 2018;20:35.

28. Witte T, Baraliakos X. Magnetic resonance imaging (MRI) diagnostics in axial spondyloarthritis. Z Rheumatol 2017;76:574-9. 